\title{
Immunoglobulin Fc
}

National Cancer Institute

\section{Source}

National Cancer Institute. Immunoglobulin FC. NCI Thesaurus. Code C13247.

A protein product that results from the digestion of antibodies with papain and is

comprised of the second and third constant regions of the antibody heavy chain. 